\title{
PENGARUH PENDIDIKAN KESEHATAN DALAM MENGKONSUMSI TABLET FE TERHADAP PERUBAHAN PENGETAHUAN DAN SIKAP IBU HAMIL DI PUSKESMAS 1 ULU PALEMBANG TAHUN 2018
}

\author{
Rohani $^{1}$, Widya Septiani ${ }^{2}$ \\ Program Studi DIII Kebidanan STIKES Mitra Adiguna \\ Komp. Kenten Permai Blok. J No.9-12 Bukit Sangkal Palembang 30114 \\ Email : ghinakiyasah@gmail.com
}

\begin{abstract}
Abstrak
Riskesdas 2013 mendapatkan anemia terjadi pada 37,1\% ibu hamil di Indonesia. 36.4\% ibu hamil di perkotaan dan 37,8\% ibu hamil di perdesaan. Untuk mencegah anemia setiap ibu hamil diharapkan mendapatkan tablet tambah darah (TTD) minimal 90 tablet selama kehamilan. Tujuan penelitian adalah untuk mengetahui ada pengaruh pendidikan kesehatan dalam mengkonsumsi tablet Fe terhadap perubahan pengetahuan dan sikap ibu hamil di Puskesmas 1 Ulu Palembang Tahun 2018. Ruang lingkup penelitian ini adalah kebidanan komunitas, rancangan yang digunakan adalah one group pretest posttest. Sampel penelitian ini adalah total populasi yaitu keseluruhan ibu hamil di Puskesmas 1 Ulu Palembang, saat penelitian, berjumlah 30 orang. Hasil yang diperoleh dari uji Wilcoxon didapatkan nilai $p=0,000$ terdapat perbedaan pengetahuan dan sikap ibu hamil sebelum dan sesudah diberikan pendidikan kesehatan tentang mengkonsumsi Tablet Fe di Puskesmas 1 Ulu Palembang Tahun 2018. Saran kepada tenaga kesehatan khususnya di bagian KIA dapat secara rutin memberikan pendidikan kesehatan kepada ibu hamil khususnya mengenai kejadian anemia pada kehamilan dan konsumsi tablet Fe, sehingga menambah pengetahuan ibu hamil mengenai kejadian anemia pada kehamilan dan merubah sikap ibu hamil menjadi positif dalam mengkonsumsi tablet Fe secara rutin.
\end{abstract}

Kata kunci : Pendidikan Kesehatan, Konsumsi Tablet Fe, Pengetahuan, Sikap Ibu Hamil Referensi : Buku 13 (2011-2014), Jurnal 9 (2012-2017)

\begin{abstract}
Riskesdas 2013 received anemia in 37.1\% of pregnant women in Indonesia. 36.4\% of pregnant women in urban areas and $37.8 \%$ of pregnant women in rural areas. To prevent anemia, every pregnant woman is expected to get a blood-added tablet (TTD) of at least 90 tablets during pregnancy. The aim of the study was to determine the effect of health education in consuming Fe tablets on changes in knowledge and attitudes of pregnant women in Palembang 1 Ulu Health Center in 2018. The scope of this study was community midwifery, the design used was one group pretest posttest. The sample of this study was the total population, namely all pregnant women at Palembang 1 Ulu Health Center, at the time of the study, 30 people. The results obtained from the Wilcoxon test obtained $p=0,000$, there were differences in knowledge and attitudes of pregnant women before and after being given health education about consuming Fe Tablets at Palembang Ulu 1 Health Center in 2018. Suggestions for health workers especially in the KIA section can routinely provide health education to pregnant women especially regarding the incidence of anemia in pregnancy and consumption of Fe tablets, thus increasing the knowledge of pregnant women regarding the incidence of anemia in pregnancy and changing the attitude of pregnant women to be positive in consuming Fe tablets regularly.
\end{abstract}

Keywords : Health Education, Fe Tablet Consumption, Knowledge, Attitudes of Pregnant

Book Reference : 13 (2011-2014), Journal : 9 (2012-2017) 


\section{PENDAHULUAN}

Anemia pada kehamilan adalah anemia karena kekurangan zat besi, dan merupakan jenis anemia yang pengobatannya relatif mudah, bahkan murah. Anemia. Anemia pada kehamilan merupakan masalah nasional karena mencerminkan nilai kesejahteraan sosial ekonomi masyarakat, dan pengaruhnya sangat besar terhadap kualitas sumber daya manusia. Anemia kehamilan disebut "Potential danger to mother and child" (potensial membahayakan ibu dan anak), karena itulah anemia memerlukan perhatian serius dari semua pihak yang terkait dalam pelayanan kesehatan pada lini terdepan (Manuaba, 2014).

Menurut WHO (World Health Organization), kejadian anemia kehamilan berkisar 20 dan $89 \%$ dengan menetapkan $\mathrm{Hb} 11 \mathrm{~g} \%$ (g/dl) sebagai dasarnya. Angka anemia kehamilan di Indonesia menunjukkan nilai yang cukup tinggi. Hoo Swie Tjiong menemukan angka anemia kehamilan $3,8 \%$ pada trimester I, 13,6\% trimester II, dan 24,8\% pada trimester III. Akrib Sukarman menemukan sebesar 40,1\% di Bogor. Bakta menemukan anemia kehamilan sebesar 50,7\% di Puskesmas kota Denpasar sedangkan Sindhu menemukan sebesar 33,4\% di Puskesmas Mengwi (Manuaba, 2014).

Riskesdas 2013 mendapatkan anemia terjadi pada $37,1 \%$ ibu hamil di Indonesia. $36.4 \%$ ibu hamil di perkotaan dan $37,8 \%$ ibu hamil di perdesaan. Untuk mencegah anemia setiap ibu hamil diharapkan mendapatkan tablet tambah darah (TTD) minimal 90 tablet selama kehamilan. Hasil PSG 2016 mendapatkan hanya 42,2\% ibu hamil yang mendapatkan TTD minimal 90 tablet lebih rendah dari target nasional tahun 2016 sebesar $85 \%$ (Kemenkes RI, 2016).

Salah satu pencegahan dan terapi anemia kehamilan adalah menambah pemasukan zat besi ke dalam tubuh dengan minum Tablet Tambah Darah (TTD). Tablet tambah darah adalah tablet besi folat (tablet $\mathrm{Fe}$ ) yang setiap tabletnya mengandung $200 \mathrm{mg}$ Ferro Sulfata tau 60 $\mathrm{mg}$ besi elemental dan $0,25 \mathrm{mg}$ asam folat. Wanita yang sedang hamil, kebutuhan zat besinya sangat tinggi sehingga perlu dipersiapkan sedini mungkin semenjak remaja. Untuk ibu hamil, minumlah 1 (satu) tablet tambah darah setiap hari paling sedikit selama 90 hari masa kehamilan dan 40 hari setelah melahirkan (Fadlun dan Feryanto, 2012).

Masalah umum pada ibu hamil dengan anemia karena adanya ketidaktahuan, ketidakmauan dan ketidakmampuan dalam mengatasi masalah kesehatannya, sehingga perlu diberikan pendidikan kesehatan yang bertujuan, meningkatkan pengetahuan (kognitif), mengubah/ memperbaiki perasaan (afektif) dan meningkatkan ketrampilan (psikomotor). Dari ketiga tujuan tersebut pada hakekatnya pendidikan kesehatan bertujuan merubah sasaran untuk hidup dalam kondisi terbaik yaitu berusaha mencapai tingkat kesehatan yang optimal. Tujuan akhir dari pendidikan kesehatan adalah agar masyarakat dapat mempraktikkan hidup sehat bagi dirinya sendiri dan bagi masyarakat, atau masyarakat dapat berperilaku hidup sehat (healthy life style) (Tarwoto dan Wasnidar, 2013).

Hasil penelitian Astuti (2012), berjudul "Pengaruh Pendidikan Kesehatan Tentang Anemia Pada Ibuhamil Terhadap Perubahan Pengetahuan Dan Sikap Ibu Hamil Dalam Mengkonsumsi Tablet Fe (ferum) di rumah Bersalin Sri Lumintu Surakarta". Menyimpulkan bahwa terdapat pengaruh pendidikan kesehatan terhadap perubahan pengetahuan ibu tentang tablet $\mathrm{Fe}$ (Ferum) dan terdapat pengaruh pendidikan kesehatan terhadap perubahan sikap ibu tentang tablet $\mathrm{Fe}$ (Ferum).

Hasil penelitian Sulistiyanti (2015), berjudul "Hubungan Tingkat Pengetahuan Ibu Hamil Tentang Anemia Dengan Kepatuhan Konsumsi Tablet $\mathrm{Fe}$ Di Wilayah Kerja Puskesmas Masaran I 
Sragen”. Menyimpulkan terdapat hubungan tingkat pengetahuan ibu hamil tentang anemia dengan kepatuhan mengkonsumsi tablet Fe di wilayah kerja Puskesmas Masaran I Sragen.

Dinas Kesehatan Kota Palembang, ibu hamil yang mengalami anemia pada tahun 2015 sebanyak 675 orang $(2,1 \%)$, tahun 2016 sebanyak 722 orang $(2,2 \%)$ dan tahun 2017 sebanyak 1.448 orang (4,9\%) (Dinkes Palembang, 2017).

Berdasarkan data dari Puskesmas 1 Ulu Palembang, ibu hamil yang mengalami anemia pada tahun 2015 sebanyak 0 orang, tahun 2016 sebanyak 2 orang $(0,3 \%)$ dan tahun 2017 sebanyak 211 orang $(5,9 \%)$ (PKM 1 Ulu, 2017).

Dari uraian diatas peneliti tertarik untuk melakukan penelitian yang berjudul "Pengaruh Pendidikan Kesehatan Dalam Mengkonsumsi Tablet Fe Terhadap Perubahan Pengetahuan dan Sikap Ibu Hamil di Puskesmas 1 Ulu Palembang Tahun 2018."

\section{METODE PENELITIAN}

\section{Ruang Lingkup Penelitian}

Ruang lingkup penelitian ini adalah kebidanan komunitas, khususnya melihat pengaruh pendidikan kesehatan tentang anemia pada ibu hamil terhadap perubahan pengetahuan dan sikap ibu hamil dalam mengkonsumsi Tablet Fe. Rancangan yang digunakan adalah one group pretest postest.

\section{Waktu Penelitian}

Penelitian ini dilaksanakan pada tanggal 09 sampai 14 April 2018.

\section{Tempat Penelitian}

Penelitian ini dilaksanakan di Puskesmas1 Ulu Palembang.

\section{Jenis Data}

\section{Data Primer}

Data primer dalam penelitian ini diperoleh dari lembar pertanyaan pre dan post test yang diisi oleh repsonden dipandu peneliti.

\section{Data Sekunder}

Penelitian menggunakan data sekunder yang diperoleh dari pihak Puskesmas1 Ulu Palembang.

\section{Teknik / Cara Pengumpulan Data}

Metode pengumpulan data dilakukan secara manual, dengan melakukan pencatatan data dari Puskesmas 1 Ulu Palembang sebagai data sekunder dan melihat lembar pertanyaan pre dan post test yang telah diisi oleh responden sebagai data primer.

\section{Populasi dan Sampel \\ Populasi}

Populasi pada penelitian ini adalah keseluruhan ibu hamil di Puskesmas 1 Ulu Palembang, saat penelitian, berjumlah 30 orang.

\section{Sampel}

Sampel penelitian ini adalah total populasi yaitu keseluruhan ibu hamil di Puskesmas 1 Ulu Palembang, saat penelitian, berjumlah 30 orang, karena yang bersedia untuk mengikuti pendidikan kesehatan sedikit dengan alasan sibuk dan tidak punya waktu.

\section{Teknik Analisis Data}

\section{Analisis Univariat}

Analisis univariat pada penelitian ini dilakukan pada tiap variabel dari hasil penelitian yaitu pengetahuan dan sikap ibu hamil dalam mengkonsumsi tablet Fe dalam tabel frekuensi dan persentase.

\section{Analisis Bivariat}

Pada penelitian ini, analisis bivariat dilakukan dengan terlebih dahulu melakukan uji normalitas data menggunakan uji Shapiro-Wilk bila sampel kurang dari 50 atau uji Kolmogorov-Smirnov bila sampel lebih dari 50, dengan ketentuan jika $p$ value $\geq$ 0,05 berarti data terdistribusi normal dan jika $p$ value $<0,05$ berarti data tidak terdistribusi normal (Dahlan, 2013).

Setelah itu untuk uji pengaruh menggunakan uji statistik $t$ test dengan tingkat kemaknaan alpha 0,05 bila data terdistribusi normal dan uji Wilcoxon bila data tidak terdistribusi normal dengan ketentuan jika $p$ value $<0,05$ berarti ada 
pengaruh dan jika jika $p$ value $\geq 0,05$ berarti tidak ada pengaruh (Dahlan, 2013).

\section{HASIL PENELITIAN}

\section{Analisis Univariat}

Analisis ini dilakukan pada tiap variabel dari hasil penelitian yaitu pengetahuan dan sikap ibu hamil sebelum dan sesudah pendidikan kesehatan dalam mengkonsumsi tablet $\mathrm{Fe}$ dalam tabel frekuensi dan persentase.

Pengetahuan Dalam Mengkonsumsi Tablet Fe

Pada penelitian ini variabel pengetahuan dalam mengkonsumsi tablet $\mathrm{Fe}$, hasil ukurnya berupa skor pengetahuan secara interval. Untuk lebih jelas terlihat pada Tabel 4.1 dibawah ini.

Tabel 4.1

Distribusi Frekuensi Responden Berdasarkan Pengetahuan Ibu Hamil Sebelum dan Setelah Pendidikan Kesehatan Dalam Mengkonsumsi Tablet Fe Di Puskesmas 1 Ulu Palembang Tahun 2018

\begin{tabular}{cccccc}
\hline N & $\begin{array}{c}\text { Skor } \\
\text { Pengeta }\end{array}$ & \multicolumn{2}{c}{ Sebelum } & \multicolumn{2}{c}{ Setelah } \\
\cline { 3 - 6 } & huan & $\mathbf{f}$ & $\%$ & $\mathbf{f}$ & $\%$ \\
\hline 1 & $1-5$ & 2 & 6,7 & 0 & 0 \\
\hline 2 & $6-10$ & 28 & 93, & 30 & 100 \\
& & & 3 & & \\
\hline & Jumlah & 30 & 100 & 30 & 100
\end{tabular}

Sumber: Hasil Penelitian tahun 2018

Dari Tabel 4.1 dapat dilihat bahwa skor pengetahuan responden setelah pendidikan kesehatan semua pada interval 6-10 berjumlah 30 orang (100\%), sementara sebelum pendidikan kesehatan hanya terdapat 28 orang $(93,3 \%)$ responden yang mendapatkan skor pengetahuan pada interval 6-10.

Sikap Ibu Hamil Dalam Mengkonsumsi Tablet Fe
Pada penelitian ini variabel sikap dalam mengkonsumsi tablet $\mathrm{Fe}$, hasil ukurnya berupa skor pengetahuan secara interval. Untuk lebih jelas terlihat pada Tabel 4.2 dibawah ini.

Tabel 4.2

Distribusi Frekuensi Responden Berdasarkan Sikap Ibu Hamil Sebelum dan Setelah Pendidikan Kesehatan Dalam Mengkonsumsi Tablet Fe Di Puskesmas 1 Ulu Palembang Tahun 2018

\begin{tabular}{cccccc}
\hline N & Skor & \multicolumn{2}{c}{ Sebelum } & \multicolumn{2}{c}{ Setelah } \\
\cline { 3 - 6 } o & Sikap & $\mathbf{f}$ & $\boldsymbol{\%}$ & $\mathbf{f}$ & $\%$ \\
\hline 1 & $41-60$ & 21 & 70 & 13 & 43,3 \\
\hline 2 & $61-80$ & 9 & 30 & 17 & 56,7 \\
\hline & Jumlah & 30 & 100 & 30 & 100
\end{tabular}

Sumber: Hasil Penelitian tahun 2018

Dari Tabel 4.2 dapat dilihat bahwa skor sikap responden setelah pendidikan kesehatan sebagian besar pada interval 61-80 berjumlah 17 orang $(56,7 \%)$, sementara sebelum pendidikan kesehatan hanya terdapat 9 orang $(30 \%)$ responden yang mendapatkan skor sikap pada interval 61-80.

\section{Analisis Bivariat}

Pada penelitian ini, sebelum analisis bivariat dilakukan dengan terlebih dahulu melakukan uji normalitas skor pengetahuan dan sikap sebelum dan setelah pendidikan kesehatan mengkonsumsi tablet Fe menggunakan uji Shapiro-Wilk, karena jumlah sampel $\leq$ 50. Adapun hasil uji sebagaimana terlihat pada tabel 4.3:

Pengetahuan Sebelum Dan Setelah Pendidikan Kesehatan

\section{Tabel 4.3}

Uji Normalitas Skor Pengetahuan Ibu Hamil Sebelum dan Setelah Pendidikan Kesehatan Dalam Mengkonsumsi 
Tablet Fe Di Puskesmas 1 Ulu Palembang Tahun 2018

\begin{tabular}{|c|c|c|c|c|}
\hline $\begin{array}{l}\mathbf{N} \\
\mathbf{0}\end{array}$ & Variabel & $\begin{array}{l}\text { Shapir } \\
\text { o-Wilk }\end{array}$ & $p$ & $\begin{array}{c}\text { Statu } \\
\text { S }\end{array}$ \\
\hline 1 & $\begin{array}{l}\text { Skor } \\
\text { pengetahu } \\
\text { an } \\
\text { sebelum } \\
\text { penkes }\end{array}$ & 0,771 & $\begin{array}{c}0,00 \\
0\end{array}$ & $\begin{array}{c}\text { Tidak } \\
\text { norm } \\
\text { al }\end{array}$ \\
\hline 2 & $\begin{array}{l}\text { Skor } \\
\text { pengetahu } \\
\text { an setelah } \\
\text { penkes }\end{array}$ & 0,327 & $\begin{array}{c}0,00 \\
0\end{array}$ & $\begin{array}{c}\text { Tidak } \\
\text { norm } \\
\text { al }\end{array}$ \\
\hline
\end{tabular}

Sumber: Hasil Penelitian tahun 2018

Berdasarkan tabel 4.3 di atas, diketahui hasil uji normalitas skor pengetahuan sebelum dan setelah pendidikan kesehatan mengkonsumsi tablet Fe mendapatkan nilai $p(0,000)<$ 0,05 , ketentuan pada test Shapiro-Wilk bila $p<\alpha 0,05$, distribusi data dinyatakan tidak normal.

Selanjutnya analisis bivariat dilakukan untuk melihat perbedaan pengetahuan hamil sebelum dan sesudah diberikan pendidikan kesehatan tentang mengkonsumsi Tablet Fe di Puskesmas 1 Ulu Palembang Tahun 2018 dengan uji Wilcoxon, dengan tingkat kemaknaan alpha 0,05 dengan ketentuan jika $p$ value $<0,05$ berarti ada perbedaan dan jika $p$ value $\geq 0,05$ berarti tidak ada perbedaan.

Tabel 4.4

Distribusi Rata-Rata Skor Pengetahuan Ibu Hamil Sebelum dan Setelah Pendidikan Kesehatan Dalam Mengkonsumsi Tablet Fe Di Puskesmas 1 Ulu

Palembang Tahun 2018

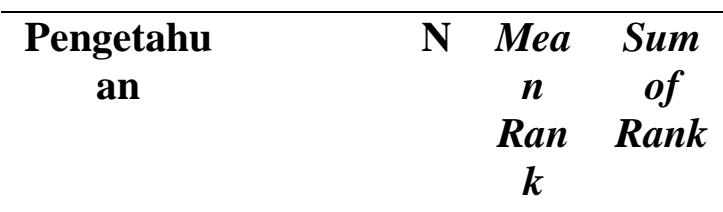

\begin{tabular}{lllll}
\hline Setelah & Negati & 0 & 0,00 & 0,00 \\
\hline
\end{tabular}

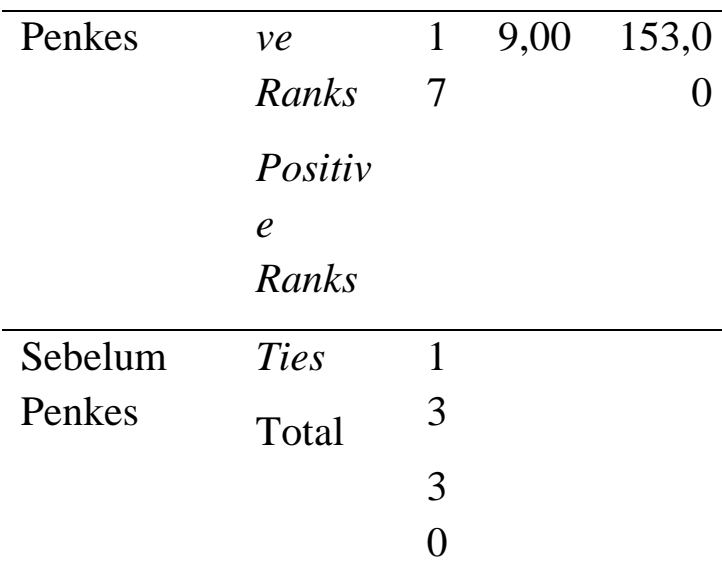

Sumber: Hasil Penelitian tahun 2018

Dari Tabel 4.4 dapat dilihat bahwa Negative Rank artinya responden dengan skor pengetahuan setelah lebih rendah dari skor pengetahuan sebelum. Positive Ranks artinya responden dengan skor pengetahuan setelah lebih tinggi dari skor pengetahuan sebelum dan Ties artinya skor pengetahuan setelah sama besarnya dengan skor pengetahuan sebelum. Berdasarkan hasil perhitungan Wilcoxon Signed Ranks Test didapatkan nilai $p$ value $($ Asymp Sig) $=0,000$ berarti pada alpha $5 \%$ terlihat ada perbedaan pengetahuan ibu hamil sebelum dan sesudah diberikan pendidikan kesehatan tentang mengkonsumsi Tablet $\mathrm{Fe}$ di Puskesmas 1 Ulu Palembang Tahun 2018.

Sikap Sebelum Dan Setelah Pendidikan Kesehatan

Tabel 4.5

Uji Normalitas Skor Sikap Ibu Hamil Sebelum dan Setelah Pendidikan

Kesehatan Dalam Mengkonsumsi Tablet Fe

Di Puskesmas 1 Ulu Palembang Tahun 2018

\begin{tabular}{clccc}
\hline $\begin{array}{c}\text { N } \\
\mathbf{o}\end{array}$ & $\begin{array}{l}\text { Variabe } \\
\mathbf{l}\end{array}$ & $\begin{array}{c}\text { Shapiro } \\
\text {-Wilk }\end{array}$ & $\boldsymbol{p}$ & Status \\
\hline 1 & $\begin{array}{l}\text { Skor } \\
\text { sikap } \\
\text { sebelum } \\
\text { penkes }\end{array}$ & 0,856 & 0,00 & Tidak \\
& & 1 & $\begin{array}{c}\text { norma } \\
1\end{array}$ \\
\hline 2 & Skor & 0,775 & 0,00 & Tidak \\
\hline
\end{tabular}




\begin{tabular}{lcc}
\hline sikap & 0 & norma \\
setelah & & 1 \\
penkes & & \\
\hline
\end{tabular}

Sumber: Hasil Penelitian tahun 2018

Berdasarkan tabel 4.5 di atas, diketahui hasil uji normalitas skor sikap sebelum dan setelah pendidikan kesehatan mengkonsumsi tablet $\mathrm{Fe}$ mendapatkan nilai $p(0,001$ dan 0,000$)<0,05$, ketentuan pada test Shapiro-Wilk bila $p$ $<\alpha 0,05$, distribusi data dinyatakan tidak normal.

Selanjutnya analisis bivariat dilakukan untuk melihat perbedaan sikap ibu hamil sebelum dan sesudah diberikan pendidikan kesehatan tentang mengkonsumsi Tablet Fe di Puskesmas 1 Ulu Palembang Tahun 2018 dengan uji Wilcoxon, dengan tingkat kemaknaan alpha 0,05 dengan ketentuan jika $p$ value $<0,05$ berarti ada perbedaan dan jika $p$ value $\geq 0,05$ berarti tidak ada perbedaan.

Tabel 4.6

Distribusi Rata-Rata Skor Sikap Ibu Hamil Sebelum dan Setelah Pendidikan Kesehatan Dalam Mengkonsumsi Tablet Fe Di Puskesmas 1 Ulu Palembang Tahun 2018

\begin{tabular}{llccr}
\hline Sikap & & N & $\begin{array}{c}\text { Mea } \\
\text { n } \\
\text { Rank }\end{array}$ & $\begin{array}{c}\text { Sum } \\
\text { of } \\
\text { Rank }\end{array}$ \\
\hline Setelah & Negativ & 0 & 0,00 & 0,00 \\
Penkes & e Ranks & 1 & 10,50 & 210,0 \\
& Positive & 0 & & 0 \\
& Ranks & & & \\
\hline Sebelu & Ties & 2 & & \\
m & Total & 0 & & \\
Penkes & & 3 & & \\
& & 0 & & \\
\hline
\end{tabular}

Sumber: Hasil Penelitian tahun 2018
Dari Tabel 4.6 dapat dilihat bahwa Negative Rank artinya responden dengan skor sikap setelah lebih rendah dari skor sikap sebelum. Positive Ranks artinya responden dengan skor sikap setelah lebih tinggi dari skor sikap sebelum dan Ties artinya skor sikap setelah sama besarnya dengan skor sikap sebelum. Berdasarkan hasil perhitungan Wilcoxon Signed Ranks Test didapatkan nilai $p$ value (Asymp Sig) $=0,000$ berarti pada alpha $5 \%$ terlihat ada perbedaan sikap ibu hamil sebelum dan sesudah diberikan pendidikan kesehatan tentang mengkonsumsi Tablet Fe di Puskesmas 1 Ulu Palembang Tahun 2018.

\section{Pembahasan \\ Pengetahuan}

Berdasarkan hasil perhitungan Wilcoxon Signed Ranks Test didapatkan nilai $p$ value (Asymp Sig) $=0,000$ berarti pada alpha $5 \%$ terlihat ada perbedaan pengetahuan ibu hamil sebelum dan sesudah diberikan pendidikan kesehatan tentang mengkonsumsi Tablet $\mathrm{Fe}$ di Puskesmas 1 Ulu Palembang Tahun 2018.

Penelitian ini sejalan dengan beberapa penelitian terdahulu antara lain: penelitian Astuti (2012), yang menyimpulkan bahwa terdapat pengaruh pendidikan kesehatan terhadap perubahan pengetahuan ibu tentang tablet $\mathrm{Fe}$ (Ferum). Pemberian informasi-informasi dari peneliti kepada responden berdampak pada peningkatan pengetahuan responden khususnya tentang tablet $\mathrm{Fe}$. Ibu-ibu hamil yang menjadi responden bertambah pengetahuanya tentang tablet $\mathrm{Fe}$, yang pada waktu sebelum diberi pendidikan kesehatan mereka ada yang tidak mengenal apa itu tablet Fe. Penelitian Wagati (2016), yang menunjukkan bahwa ada hubungan antara tingkat pengetahuan tentang anemia dengan perilaku ibu hamil dalam mengkonsumsi tablet $\mathrm{Fe}$ dengan Zhitung $>$ Ztabel $=2.33>0.4013$. Ibu hamil diharapkan sering melakukan pemeriksaan kehamilan sehingga dapat mendapatkan informasi tentang tablet $\mathrm{Fe}$, 
dan mengkonsumsi tablet Fe secara rutin selama kehamilan. Penelitian Theng, Zakaria dan Yusof (2017), menunjukkan tingkat pengetahuan pada konsumsi suplemen zat besi adalah tinggi 58,3\%. Tingkat pengetahuan tentang konsumsi suplemen zat besi sangat terkait dengan konsumsi suplemen zat besi $(\chi=16,717$, $\mathrm{p}<0,001)$.

Namun, penelitian ini tidak sejalan penelitian Purnamasari (2016), yang menunjukkan pengetahuan tidak ada yang berhubungan dengan kepatuhan ibu hamil dalam mengkonsumsi tablet $\mathrm{Fe}$ dengan $\mathrm{p}$ value > 0,05. hal ini mungkin terjadi karena selain pengetahuan masih ada variabel lain yang lebih berhubungan dengan kepatuhan ibu hamil dalam mengkonsumsi tablet Fe.

Pendidikan kesehatan ialah suatu upaya atau kegiatan untuk menciptakan perilaku masyarakat yang kondusif untuk kesehatan. Artinya pendidikan kesehatan berupaya agar masyarakat menyadari atau mengetahui bagaimana cara memelihara kesehatan mereka, bagaimana menghindari atau mencegah hal-hal yang merugikan kesehatan mereka dan kesehatan orang lain, ke mana seharusnya mencari pengobatan bilamana sakit dan sebagainya (Notoatmodjo, 2012).

Salah satu tujuan pendidikan kesehatan adalah meningkatkan pengetahuan (Kognitif), tindakan petugas pemberi pendidikan kesehatan dalam meningkatkan pengetahuan klien diantaranya adalah menjelaskan, memberikan informasi, menyarankan, mendiskusikan masalah kesehatan klien (Tarwoto dan Wasnidar, 2013).

\section{Sikap}

Berdasarkan hasil perhitungan Wilcoxon Signed Ranks Test didapatkan nilai $p$ value (Asymp Sig) $=0,000$ berarti pada alpha 5\% terlihat ada perbedaan sikap ibu hamil sebelum dan sesudah diberikan pendidikan kesehatan tentang mengkonsumsi Tablet Fe di Puskesmas 1 Ulu Palembang Tahun 2018.
Penelitian ini sejalan dengan beberapa penelitian terdahulu antara lain: penelitian Astuti (2012), yang menyimpulkan bahwa terdapat pengaruh pendidikan kesehatan terhadap perubahan sikap ibu tentang tablet $\mathrm{Fe}$ (Ferum). Karena peningkatan informasi responden tentang tablet $\mathrm{Fe}$, berdampak pada peningkatan pengetahuan responden tentang tablet Fe. Setelah mereka memahami tentang tablet $\mathrm{Fe}$, maka responden akan melakukan evaluasi pada perilaku mereka dalam mengkonsumsi tablet Fe. Ketika mereka merasa bahwa perilaku mereka kurang tepat, maka mereka akan memilih perilaku-perilaku yang lebih baik, sehingga meningkatkan sikap mereka terhadap konsumsi table Fe. Penelitian Theng, Zakaria dan Yusof (2017), menunjukkan sikap pada konsumsi suplemen zat besi adalah tinggi $54,2 \%$. Sikap terhadap konsumsi suplemen zat besi menunjukkan hubungan dengan konsumsi suplemen zat besi $(\chi 2=$ $8,449, \mathrm{p}<0,01)$.

Namun penelitian ini tidak sejalan dengan beberapa penelitian terdahulu antara lain: penelitian Purnamasari (2016), yang menunjukkan sikap tidak ada yang berhubungan dengan kepatuhan ibu hamil dalam mengkonsumsi tablet $\mathrm{Fe}$ dengan $\mathrm{p}$ value $>0,05$. Karena sikap merupakan predisposisi evaluatif yang banyak menentukan bagaimana individu berperilaku, akan tetapi sikap dan perilaku sering kali berbeda. Hal ini dikarenakan perilaku tidak hanya ditentukan oleh sikap semata, akan tetapi oleh berbagai faktor eksternal lainnya. Penelitian Nivedita dan Shanthini (2016), menunjukkan sebanyak 1/5 peserta belum menerima informasi pendidikan mengenai anemia dari sumber apa pun. Tetapi sikap keseluruhan terhadap manfaat suplementasi zat besi pada umumnya baik dan $74,36 \%$ mengaku telah mengkonsumsi suplementasi zat besi secara teratur

Tujuan pendidikan kesehatan antara lain mengubah/ memperbaiki perasaan (Afektif), perubahan afektif misalnya 
adanya perubahan sikap, pendapat, keyakinan dan nilai-nilai yang dimiliki klien (Tarwoto dan Wasnidar, 2013).

Perubahan sikap meliputi tahap pertama yaitu unfreezing, yaitu ketika responden menyadari bahwa tindakannya selama ini kurang tepat tentang tablet Fe. Tahap kedua yaitu changing (perubahan) yaitu setelah berubahnya kesadaran responden tentang konsumsi tablet $\mathrm{Fe}$. Perubahan sikap ini dipengaruhi oleh pengetahuan yang diterima ibu serta pengaruh dari lingkungan sekitar baik informasi maupun pengaruh orang lain. Tahap ketiga yaitu re-freezing, tahap ini responden mengevaluasi sikapnya terhadap penatalaksanaan konsumsi tablet Fe (Niven dalam Astuti, 2012).

\section{SIMPULAN DAN SARAN}

\section{Simpulan}

1. Distribusi frekuensi skor pengetahuan responden sebelum pendidikan kesehatan hanya terdapat 28 orang $(93,3 \%)$ responden yang mendapatkan skor pengetahuan pada interval 6-10 dan setelah pendidikan kesehatan semua pada interval 6-10 berjumlah 30 orang $(100 \%)$.

2. Distribusi frekuensi skor sikap responden sebelum pendidikan kesehatan hanya terdapat 9 orang (30\%) responden yang mendapatkan skor sikap pada interval 61-80 dan setelah pendidikan kesehatan sebagian besar pada interval 61-80 berjumlah 17 orang $(56,7 \%)$.

3. Dari hasil uji Wilcoxon didapatkan nilai $p=0,000$ berarti pada alpha $5 \%$ terlihat ada perbedaan pengetahuan ibu hamil sebelum dan sesudah diberikan pendidikan kesehatan tentang mengkonsumsi Tablet $\mathrm{Fe}$ di Puskesmas 1 Ulu Palembang Tahun 2018.

Dari hasil uji Wilcoxon didapatkan nilai $p=0,000$ berarti pada alpha 5\% terlihat ada perbedaan sikap ibu hamil sebelum dan sesudah diberikan pendidikan kesehatan tentang mengkonsumsi Tablet Fe di Puskesmas 1 Ulu Palembang Tahun 2018.

\section{Saran}

\section{Bagi Pihak Puskesmas 1 Ulu Palembang}

Diharapkan kepada tenaga kesehatan khususnya di bagian KIA dapat secara rutin memberikan pendidikan kesehatan kepada ibu hamil khususnya mengenai kejadian anemia pada kehamilan dan konsumsi tablet $\mathrm{Fe}$, sehingga menambah pengetahuan ibu hamil mengenai kejadian anemia pada kehamilan dan merubah sikap ibu hamil menjadi positif dalam mengkonsumsi tablet $\mathrm{Fe}$ secara rutin.

\section{Bagi Institusi Pendidikan}

Agar dapat menjadi hasil penelitian ini sebagai bahan acuan dan merupakan informasi lengkap yang bermanfaat untuk menambah pengetahuan mahasiswa khususnya Program Studi Diploma III Kebidanan.

\section{Bagi Peneliti Yang Akan Datang}

Agar dapat menjadikan penelitian ini sebagai bahan acuan untuk meneruskan penelitian mengenai pengetahuan dan sikap ibu hamil dalam mengkonsumsi tablet $\mathrm{Fe}$ juga dipengaruh faktor-faktor lain yang belum sempat diteliti pada penelitian ini, sehingga penelitian ini terus berkembang dan semakin akurat hasilnya.

\section{DAFTAR PUSTAKA}

Alifah, Rizqi Nur. 2016. Faktor-Faktor Yang Mempengaruhi Kepatuhan Ibu Hamil Mengkonsumsi Tablet $\mathrm{Fe}$ di Puskesmas Gamping 2. Naskah Publikasi Program Studi Ilmu Keperawatan Fakultas Kedokteran Dan Ilmu Kesehatan Universitas Muhammadiyah Yogyakarta.

Astutik, Esthi Widi. 2012. Pengaruh Pendidikan Kesehatan Tentang Anemia Pada Ibu Hamil Terhadap Perubahan Pengetahuan dan Sikap Ibu Hamil Dalam Mengkonsumsi Tablet Fe (Ferum) di Rumah Jurnal Kesehatan dan Pembangunan, Vol. 9, No.18, Juli 2019 
Bersalin Sri Lumintu Surakarta. Naskah Publikasi Fakultas Ilmu Kesehatan Muhammadiyah Surakarta.

Azwar, Saifuddin. 2011. Sikap Manusia Teori dan Pengukurannya. Yogyakarta: Pustaka Pelajar.

Azwar, Saifuddin. 2014. Metode Penelitian. Yogyakarta: Pustaka Pelajar.

Fadlun dan Feryanto Achmad. 2012. Asuhan Kebidanan Patologis. Jakarta: Salemba Medika.

Fuady, Mardhatillah dan Bangun Datten. 2013. Hubungan Pengetahuan Ibu Hamil Tentang Anemia Defisiensi Besi Terhadap Kepatuhan Mengkonsumsi Tablet Zat Besi. EJournal FK USU, Vol 1 No 1 (Februari 2013).

Budiman dan Riyanto Agus. 2013. Kapita Selekta Kuesioner Pengetahuan Sika dalam Penelitian Kesehatan. Jakarta: Salemba Medika.

Dahlan, Sopiyudin M. 2013. Statistik Untuk Kedokteran Dan Kesehatan. Jakarta: Salemba Medika.

Handayani, Desy dan Rumiyati Eni. 2014. Faktor-Faktor Yang Mempengaruhi Tingkat Kepatuhan Ibu Multigravida Dalam Mengkonsumsi Tablet Fe Di Puskesmas Polanharjo, Klaten. Jurnal KesMaDaSka - Januari 2014

Hani, Ummi, Jiarti Kusbandiyah, Marjati dan Yulifah Rita. 2011. Asuhan Kebidanan Pada Kehamilan Fisiologis. Jakarta: Salemba Medika.

Hidayat, Aziz Alimul. 2014. Metode Penelitian Kebidanan dan Teknik Analisis Data Edisi 2. Jakarta: Salemba Medika.

Kamidah. 2015. Faktor-Faktor Yang Mempengaruhi Kepatuhan Ibu Hamil Mengkonsumsi Tablet Fedi Puskesmas Simo Boyolali. Gaster Vol. XII No. 1 Februari 2015.

Kemenkes RI. 2017. Profil Kesehatan Indonesia Tahun 2016.

Mangkuji, Betty, Ginting Idau, Suswaty, Lubis Rismahara dan Wildan. 2013.
Asuhan Kebidanan 7 Langkah SOAP. Jakarta: EGC.

Manuaba, Ida Ayu Chandra, Manuaba Ida Bagus Gde Fajar dan Manuaba Ida Bagus Gde. 2014. Ilmu Kebidanan, Penyakit Kandungan, dan KB, Untuk Pendidikan Bidan Edisi 2. Jakarta : EGC.

Nivedita K dan Shanthini Fatima N. 2016. Knowledge, Attitude And Practices Of Pregnant Women Regarding Anemia, Iron Rich Diet And Iron Supplements And Its Impact On Their Hemoglobin Levels. International Journal of Reproduction, Contraception, Obstetrics and Gynecology. Int J Reprod Contracept Obstet Gynecol. 2016 Feb;5(2):425431

Notoatmodjo, Soekidjo. 2012. Metodologi Penelitian Kesehatan. Jakarta : Rineka Cipta.

Notoatmodjo, Soekirdjo. 2012. Promosi Kesehatan dan Perilaku Kesehatan. Jakarta: Salemba Medika.

Purnamasari, Gilang. 2016. Hubungan Pengetahuan dan Sikap Terhadap Kepatuhan Ibu Hamil Dalam Mengkonsumsi Tablet $\mathrm{Fe} d i$ Puskesmas Bogor Tengah. Jurnal Kebidanan dan Ilmu Kesehatan Volume 3/ Nomor 3/ November 2016.

Sudarti. 2013. Gizi dan Kesehatan Masyarakat Edisi Revisi. Jakarta: Rajawali Pers.

Sulistiyanti, Anik. 2015. Hubungan Tingkat Pengetahuan Ibu Hamil Tentang Anemia Dengan Kepatuhan Konsumsi Tablet $\mathrm{Fe}$ di Wilayah Kerja Puskesmas Masaran I Sragen. Jurnal Kebidanan dan Ilmu Kesehatan Volume 2/ Nomor 2/ November 2015.

Tarwoto dan Wasnidar. 2013. Buku Saku Anemia Pada Ibu Hamil Konsep dan Penatalaksanaan. Jakarta: Trans Info Media. 